\title{
Improved Glycemic Control Observed in Children with Type 1 Diabetes Following the Introduction of Smart Insulin Pens: A Real-World Study
}

\author{
Peter Adolfsson (D) - Viktor Björnsson · Niels Væver Hartvig • \\ Anne Kaas · Jonas Bech Møller · Elsa Ogionwo Lange
}

Received: September 15, 2021 / Accepted: October 20, 2021 / Published online: November 8, 2021

(c) The Author(s) 2021

\begin{abstract}
Introduction: Many challenges are associated with optimizing glycemic control in pediatric patients with type 1 diabetes (T1D); combining data from smart insulin pens and continuous glucose monitoring (CGM) could mitigate some of these obstacles.
\end{abstract}

Methods: This one-arm, prospective, observational study investigated the effects of introducing a smart pen on glycemic control in pediatric patients with T1D who were using CGM. Children and adolescents with T1D who

Supplementary Information The online version contains supplementary material available at https:// doi.org/10.1007/s13300-021-01177-w.

P. Adolfsson $(\varangle) \cdot$ V. Björnsson · E. Ogionwo Lange Department of Pediatrics, The Hospital of Halland, Kungsbacka, Tölövägen 5, 43480 Kungsbacka, Sweden

e-mail: peter.adolfsson@regionhalland.se

P. Adolfsson · V. Björnsson

Sahlgrenska Academy, University of Gothenburg, Gothenburg, Sweden

N. V. Hartvig

Data Science, Novo Nordisk A/S, Søborg, Denmark

A. Kaas

Medical \& Science, Novo Nordisk A/S, Søborg,

Denmark

J. B. Møller

Digital Health, Novo Nordisk A/S, Søborg, Denmark had been prescribed a smart pen for basal and/ or bolus insulin injections were enrolled from three clinics in Sweden. Outcomes compared between baseline and follow-up ( $\geq 12$ months) included: mean numbers of daily (over $24 \mathrm{~h}$ ) and nocturnal hypoglycemic or hyperglycemic events; time above range (TAR; $>180 \mathrm{mg} / \mathrm{dL}$ ); time below range (TBR; level 1: 54 to $<70 \mathrm{mg}$ / $\mathrm{dL}$; level 2: $<54 \mathrm{mg} / \mathrm{dL}$ ); time in range (TIR; $70-180 \mathrm{mg} / \mathrm{dL}$ ); and missed bolus-dose (MBD) meals.

Results: Overall, 39 patients were included. Mean numbers of daily hypoglycemic events $(-31.4 \% ; p=0.00035)$ and nocturnal hypoglycemic events $(-24.4 \% ; p=0.043)$ were significantly reduced from baseline to follow-up. Mean daily TBR level 2 was reduced from $2.82 \%$ at baseline to $2.18 \%$ at follow-up ( -0.64 percentage points; $p=0.025)$. There were no statistically significant changes in number of daily hyperglycemic events, MBD meals, TIR, TAR, or TBR level 1.

Conclusions: Introducing smart insulin pens was associated with a reduced number of hypoglycemic events and decreases in TBR level 2 , demonstrating a potential benefit for glycemic control in pediatric patients.

Keywords: Adolescent; Biomedical technology; Child; Diabetes mellitus type 1; Insulin; Smart insulin pens 


\section{Key Summary Points}

Why carry out this study?

Optimizing glycemic control is challenging for many pediatric patients with type 1 diabetes (T1D); combining data from smart insulin pens and continuous glucose monitoring (CGM) could mitigate some of these obstacles.

This one-arm, prospective, real-world observational study investigated the effects of introducing a smart pen on glycemic control in pediatric patients with T1D who were already using CGM.

Outcomes were compared between baseline and follow-up ( $\geq 12$ months) and included hypoglycemic events (events over $24 \mathrm{~h}$ and nocturnal events), time above range, time below range (TBR), and time in range.

\section{What was learned from the study?}

This real-world study demonstrated that introducing the smart insulin pen could have a positive impact on glycemic control in pediatric patients with T1D by reducing the number of hypoglycemic events (total over $24 \mathrm{~h}$ and nocturnal events) and decreasing the proportion of TBR level 2.

Larger controlled studies stratified by age may be required to confirm the results of this investigation.

\section{INTRODUCTION}

Treatment of type 1 diabetes (T1D) in children and adolescents requires either an intensive regimen of multiple daily injections (MDIs) of basal and bolus insulin or continuous subcutaneous insulin infusion [1-3]. Adherence to insulin therapy can support optimal glycemic control in pediatric patients with T1D [4].
Conversely, an earlier age of disease onset or poor early glycemic control might increase the risk of vascular complications [5-7]. Despite this evidence, poor adherence to insulin therapy, and difficulties with achieving glycated hemoglobin (HbA1c) targets, remain a challenge for children and adolescents with T1D [3, 8-15].

In clinical practice, information regarding the actual insulin dose delivered and the precise timing of each insulin injection is invariably incomplete or inaccurate in patients using MDIs, presenting a barrier to optimizing glycemic control [16]. Improvements in monitoring and data-collection and data-visualization processes could, therefore, aid diabetes management by allowing patients and healthcare professionals (HCPs) to monitor their dosing schedules more accurately.

Continuous glucose monitoring (CGM) can provide accurate and timely data on dynamic glycemic changes throughout the day, and is associated with lower mean HbA1c levels in young patients and adults [17, 18]. Furthermore, smart insulin pens provide a record of the exact time of, and the amount of insulin administered in every dose, and the collected data can be downloaded to a suitable database and viewed in a specialized program. Combining data from CGM and smart insulin pens could provide a more complete picture of diabetes management, thereby helping HCPs to identify the reasons for inadequate glycemic control and subsequently optimize patients' treatment. In a previous study conducted in adults, after the introduction of a smart pen for administration of basal and/or bolus insulin injections, patients spent more time in range (TIR; $70-180 \mathrm{mg} / \mathrm{dL}$ ) and less time in hypoglycemia $(<54 \mathrm{mg} / \mathrm{dL})$ and hyperglycemia (>180 mg/dL), and had fewer missed bolusdose (MBD) injections [19].

Here, we describe the evolution of glycemic parameters following the introduction of the smart pen in a pediatric population with T1D using CGM. 


\section{METHODS}

\section{Study Design}

In this one-arm, prospective, observational, proof-of-concept, real-world study, children and adolescents with T1D were enrolled from three secondary care pediatric diabetes clinics in Sweden from May 2017 to April 2019. All healthcare interventions, including medications and medical aids, are provided free of charge for children and adolescents in Sweden. Eligible patients ( $<18$ years of age) were using CGM and had been prescribed a smart pen (NovoPen ${ }^{\circledR}$ 6; Novo Nordisk, Bagsværd, Denmark) for administration of basal and/or bolus insulin. Swedish Ethics Committee approval (2019-01270) was obtained before any studyrelated activities were initiated. Written informed consent was obtained from each participant, allowing Glooko Inc. (Mountain View, CA, USA) to collect data and enabling analyses of the participants' data. The trial was conducted in accordance with the Declaration of Helsinki of 1964 and its latest revision.

At baseline, patients received a smart pen delivering basal insulin (insulin degludec U100 or insulin detemir; both Novo Nordisk) and/or bolus insulin (human insulin or insulin aspart; Novo Nordisk). Permitted CGM devices included intermittently scanned systems and realtime systems according to routine clinical practice, and most patients were already using CGM in the period before study initiation. Data collected by the smart pen included the number of units injected, and the date and time of administration. These data were uploaded either at home or using an in-clinic system (Glooko Diasend; Glooko Inc.) during HCP visits to transfer data from the pen to the server (Electronic Supplementary Material [ESM] Fig. 1). Data were then accessed via the web portal during HCP visits so that the patients/caregivers and HCPs could assess injection and CGM data together (Fig. 1).

To conduct a longitudinal analysis, and because the HCP visit times were not known with certainty, the time after baseline was grouped into quarters. The baseline period
(0-3 months [0-91 days, quarter 1]) described the time period after the first dose was administered with the smart pen. The following quarters (3-6 months [92-182 days, quarter 2]; 6-9 months [183-273 days, quarter 3]; 9-12 months [274-365 days, quarter 4], etc.) were compared with the baseline period to evaluate the long-term change in treatment pattern and glycemic control after introduction of the smart pen. For the follow-up occurring 12 months from baseline or later, the quarters in this period were grouped together as a single follow-up period in the analysis ( $\geq 366$ days, quarter $\geq 5$ ) (Fig. 2).

\section{Outcomes}

The following parameters were compared between baseline and follow-up: incidence of hypoglycemia and nocturnal hypoglycemia; percentage TIR; percentage time below range (TBR); percentage time above range (TAR); changes in mean glucose level; and number of MBD meals.

A clinically significant (level 2 [L2]) hypoglycemic event was defined as any period with readings below the threshold $(<54 \mathrm{mg} / \mathrm{dL})$ lasting for $\geq 15 \mathrm{~min}$ [20]. The episode was considered to have ended when the readings were $\geq 70 \mathrm{mg} / \mathrm{dL}$, or the readings were missing for $\geq 15 \mathrm{~min}$. If the signal was missing for $\geq$ $15 \mathrm{~min}$, the missing signal was considered to indicate two hypoglycemic events because it was unknown whether the hypoglycemic episode had ended or not in the missing period. Total daily hypoglycemic events were defined as events that occurred over a 24-h period, whereas nocturnal hypoglycemic events were defined as events that started between the times 23:00 and 05:59 hours. A hyperglycemic event was defined as any period with readings above the threshold ( $>180 \mathrm{mg} / \mathrm{dL}$ ) with a duration of $\geq 15$ min [20].

TIR was defined as the proportion of time in which blood glucose values were within the range $70-180 \mathrm{mg} / \mathrm{dL}$. A $5 \%$ increase in TIR was considered to be associated with clinically significant benefits [21]. Time in hypoglycemia was defined according to glycemic thresholds at 


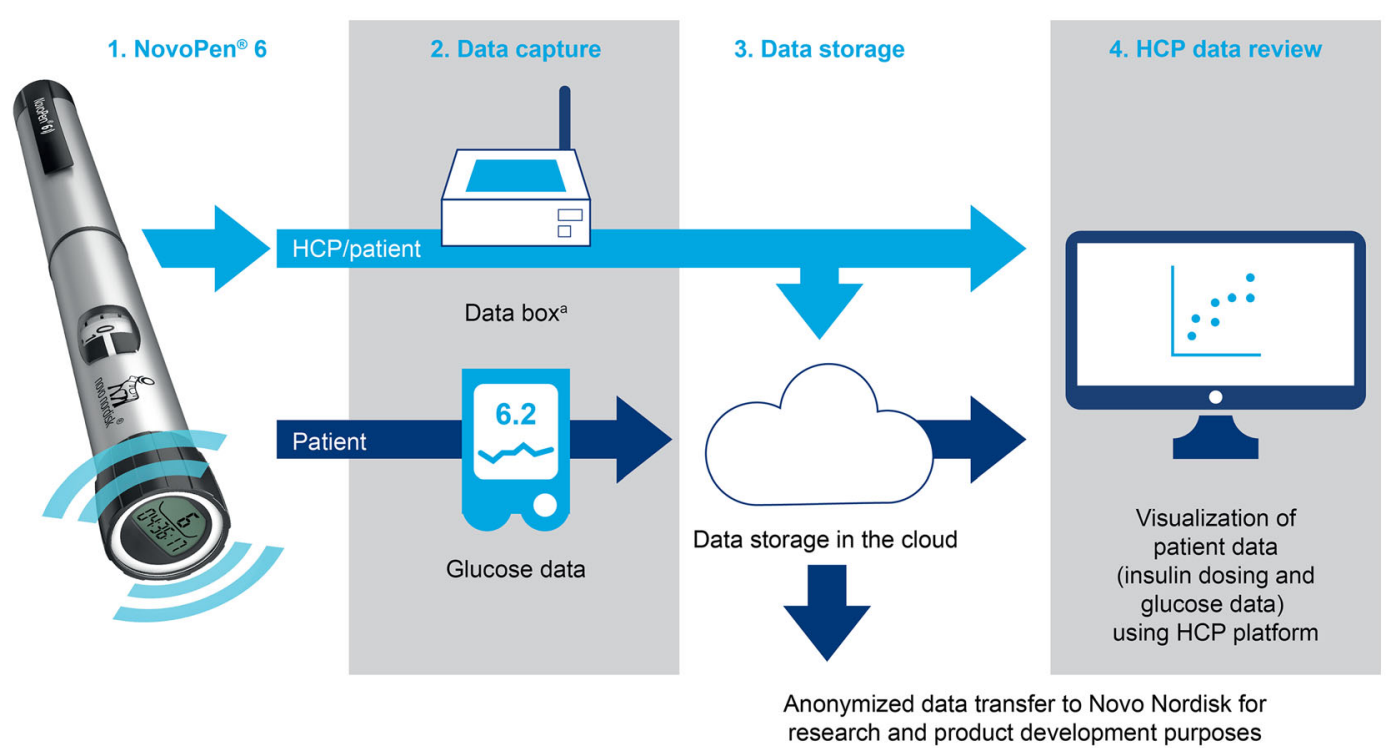

Fig. 1 Data flow during the study. ${ }^{a}$ Data uploads could be at home or in the clinic. HCP healthcare professional
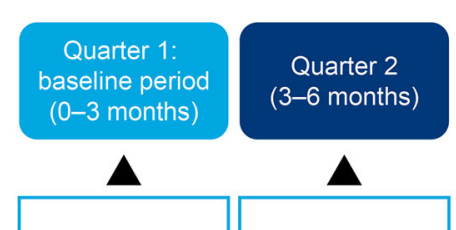
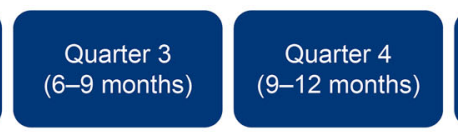

$\Delta$

\section{Home uploads and HCP visits of varying frequencies}

Data available for:

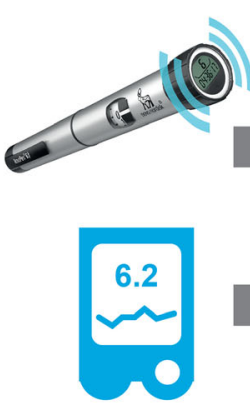

Fig. 2 Study design. HCP visits were conducted according to routine clinical practice, which, for pediatric patients in Sweden, consists of visits approximately every 3 months, with flexibility depending on the level of glycemic control

level 1 (L1; 54 to $<70 \mathrm{mg} / \mathrm{dL}$ ) and L2, and total TBR was the proportion of time spent in hypoglycemia L1 or L2 over a 24-h period. and the patient's wishes and needs. ${ }^{\text {a }}$ Data collected during quarters 5-8 ( $\geq 12$ months). ${ }^{\mathrm{b}}$ Including intermittent scanning CGM. CGM continuous glucose monitoring, $H C P$ healthcare professional

Hyperglycemia was defined as blood glucose values $>180 \mathrm{mg} / \mathrm{dL}$, and TAR was the proportion of time in hyperglycemia over a 24-h 
period. The coefficient of variation $(\% \mathrm{CV})$ was calculated to determine glycemic variability; a higher \%CV was representative of greater fluctuation in CGM and higher daily glycemic variability.

To determine whether bolus doses were being administered in a timely manner, mealtimes were detected from the CGM signal using the clinically validated Glucose Rate Increase Detector algorithm [22]. A MBD meal was defined as no bolus injection within a time window of $15 \mathrm{~min}$ before to $60 \mathrm{~min}$ after the start of a meal.

Case data, including injection data and CGM profiles, were identified to illustrate the types of patient-level data that were presented to the participants during the study. These data demonstrate the types of information that can be obtained and considered by HCPs and patients, as well as the informed treatment management decisions that can be made.

\section{Statistical Analysis}

CGM data were aggregated to daily (24-h) outcomes, excluding days with unacceptable CGM coverage $(<70 \%$ over $24 \mathrm{~h})$.

The proportions of TIR, TBR, TAR, and mean glycemic level and glycemic variability were analyzed based on restricted maximum likelihood in a linear mixed model, with quarter as a fixed effect, patient ID and quarter nested in patient ID as random effects, and an exponential residual covariance function. The numbers of total daily and nocturnal hypoglycemic events and meals with MBDs were analyzed based on a generalized linear mixed model, using the Poisson distribution with quarter as fixed effect and patient ID and quarter nested in patient ID as random effects.

Quarters 5-8 ( $\geq 2$ months after the baseline period) in the follow-up period were restricted to the same mean level (quarter $\geq 5$ ). The change from the baseline period (quarter 1) to the subsequent quarters and follow-up period was estimated with 95\% confidence intervals (CIs).

\section{RESULTS}

\section{Patient Characteristics}

Of 52 pediatric patients treated with the smart insulin pen, 13 were excluded from these analyses ( 7 patients had participated in a separate study and 6 had no CGM data that could be linked with their pen data). Therefore, 39 patients were included, providing 9474 days of acceptable CGM data. In total, 6942 days of insulin data ( 178 days per patient) were analyzed. Baseline patient characteristics and study parameters are shown in Table 1 . Of the 39 included patients, 22 (56\%), 15 (38.46\%), and one patient(s), respectively, received their treatment from Kungsbacka, Halmstad, and Borås; the public healthcare facility for one patient was "Unknown". Regarding the type of CGM device, 23 patients (59\%; $n=23 / 39)$ used an intermittently scanned CGM device (isCGM), with 15-min intervals between readings, and 16 patients $(41 \% ; n=16 / 39)$ used a realtime CGM device (rt-CGM), with 5-min intervals between readings.

\section{Glycemic Data}

During the study, there were reductions in the numbers of overall daily hypoglycemic events (over $24 \mathrm{~h}$ ) and nocturnal hypoglycemic events relative to baseline. The mean overall number of hypoglycemic events decreased from 0.36 at baseline to 0.25 at quarter $\geq 5$, representing a statistically significant mean change from baseline of $-31.4 \% \quad(95 \%$ CI $-44.2,-15.7$; $p=0.00035$ ) (Table 2; Fig. 3a). Similarly, the mean number of nocturnal hypoglycemic events decreased from 0.086 at baseline to 0.065 at quarter $\geq 5$, representing a statistically significant mean change from baseline of $-24.4 \%$ (95\% CI $-42.3,-0.9 ; p=0.043$ ) (Table 2; Fig. 3b). The incidence of overall hypoglycemic events and nocturnal hypoglycemic events decreased over the course of the study, with numerical reductions in the numbers of events at quarters 2 and 3 , and significant reductions at quarter 4 and $\geq 5$ (Fig. 3). From baseline to quarter $\geq 5$, a slight but nonstatistically 
Table 1 Patient characteristics

\begin{tabular}{ll}
\hline Parameters & Patients with CGM data $(\boldsymbol{N}=\mathbf{3 9})$ \\
\hline Age $^{\mathrm{a}}$ (years), mean (range) & $14.5(9,17)$ \\
Female, $n(\%)$ & $20(51)$ \\
Acceptable $^{\mathrm{b}}$ CGM days, $n(n / N)^{\mathrm{c}}$ & $9474(242.9)$ \\
Days with insulin data, $n(n / N)^{\mathrm{d}}$ & $6942(178.0)$ \\
Type of smart pen & \\
Basal and bolus & 24 \\
Basal only & 1 \\
Bolus only & 9 \\
Other & \\
Study duration, pen usage (days), mean (range) & 5 \\
Time between uploads (days), median (IQR) & $343.9(8,610)$ \\
\hline
\end{tabular}

$C G M$ continuous glucose monitoring, IQR interquartile range

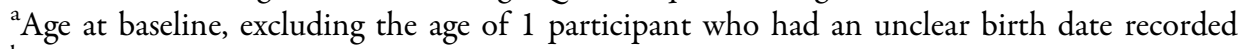

${ }^{b}$ Defined as CGM coverage $\geq 70 \%$ over the 24 -h period

${ }^{c}$ The median number of CGM days per patient was 246 days (IQR 148, 344)

${ }^{\mathrm{d}}$ The median number of days with pen injection and CGM data was 166 days (IQR 46, 288)

${ }^{\mathrm{e}}$ Five patients were registered with neither bolus nor basal pens specified in the data analyzed; consequently, data from these patients were not incorporated in the analyses of both bolus and basal injections. Of these 5 patients, 3 appeared to have a bolus insulin pen only, but with unspecified insulin type and were, therefore, not included in the bolus analyses. The other 2 patients had both basal and bolus pens in the study period, but did not have any injection data on the CGM days included in the study and were, therefore, also not incorporated in the bolus and basal analyses

significant increase in the number of overall hyperglycemic events was observed, with an estimated mean change from baseline of $6.3 \%$ $(95 \%$ CI $-0.2,13.1 ; p=0.058)$ (Table 2$)$.

The proportion of TBR L2 reduced throughout the study. The mean percentage TBR L2 reduced from $2.82 \%$ per day at baseline to $2.18 \%$ per day at quarter $\geq 5$, representing a statistically significant mean change from baseline of -0.6 percentage points (\%-points) (95\% CI $-1.19,-0.08 ; p=0.025)$, equivalent to approximately $-0.14 \mathrm{~h}$ daily (Table 2; Fig. 4). Numerical reductions in the TBR L2 were observed at quarters 2 and 3, and statistically significant reductions were observed at quarter 4 and $\geq 5$ (Fig. 4).

At quarter $\geq 5$, there were no statistically significant changes from baseline in total daily
TIR, TAR, or TBR L1. In addition, no statistically significant changes from baseline were observed in mean glucose levels $(p=0.24)$ and $\% \mathrm{CV}$ $(p=0.074)$ (Table 2).

\section{Doses and Dose Timing}

Among 14 patients who administered bolus insulin injections via smart pen with a followup to quarter $\geq 5$, there were no statistically significant changes in the mean daily number of bolus insulin injections from baseline to the quarter $\geq 5$ follow-up (4.98 vs. 4.84 doses per day). Furthermore, there were no statistically significant changes from baseline in the mean daily number of MBD meals ( 0.73 per day at baseline vs. 0.74 per day at follow-up) (Table 3 ). 


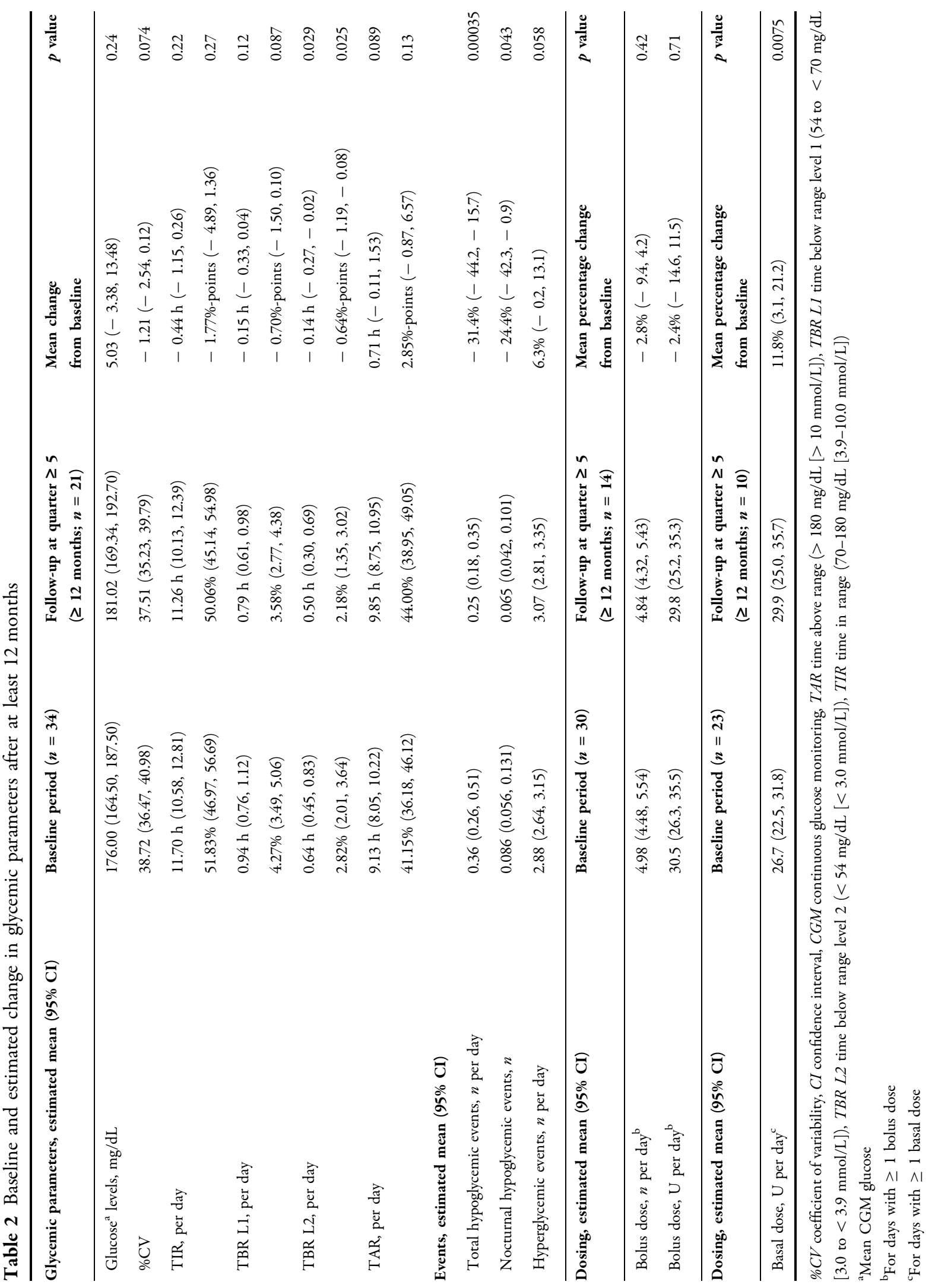




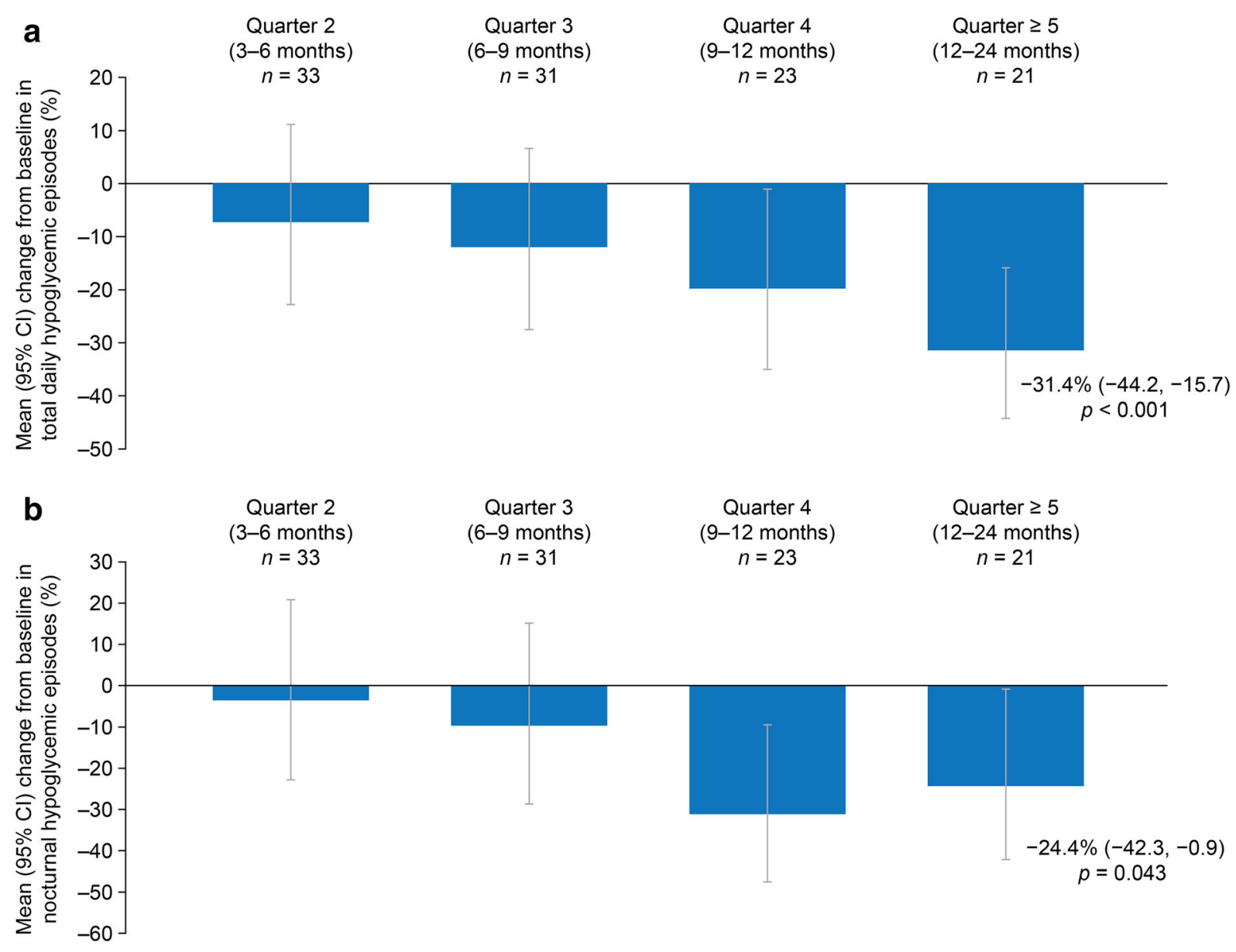

Fig. 3 Mean change from baseline in the number of (a) daily (total over 24-h period) and (b) nocturnal hypoglycemic episodes. $C I$ confidence interval

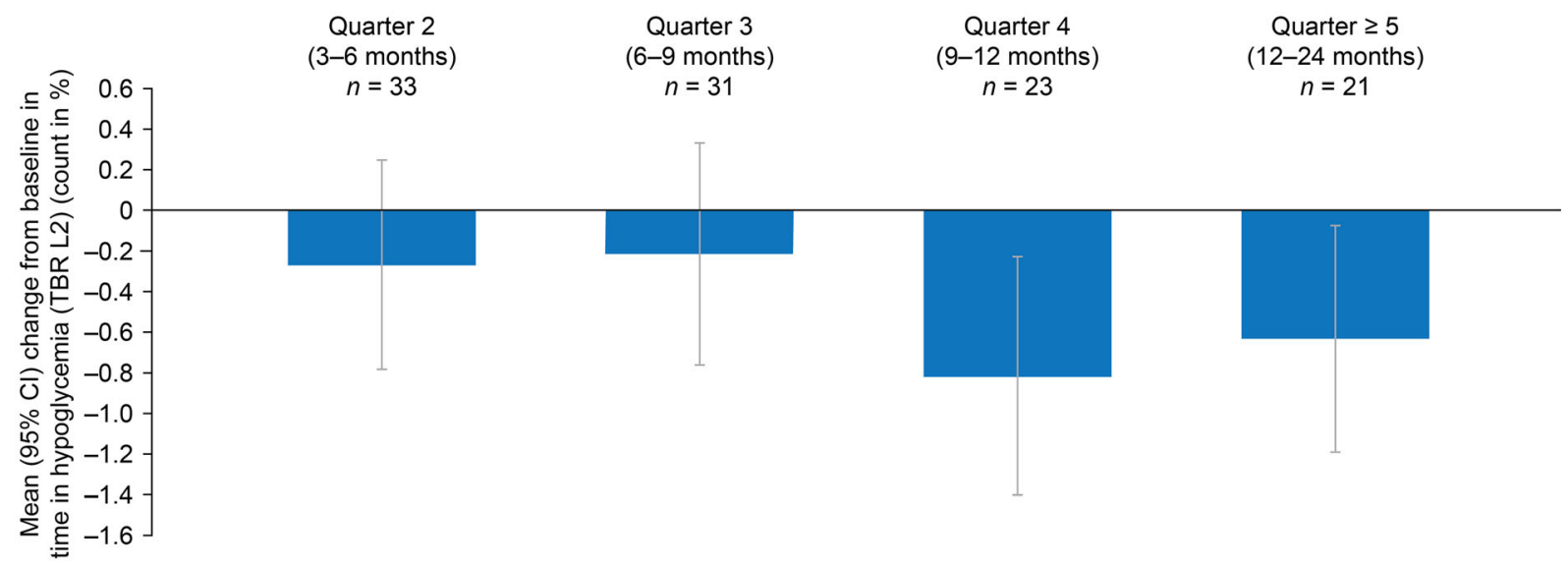

Fig. 4 Mean change from baseline in the TBR L2 per day. CI confidence interval, TBR L2 time below range level 2 $(<54 \mathrm{mg} / \mathrm{dL}[<3.0 \mathrm{mmol} / \mathrm{L}])$ 
Table 3 Mean change in the numbers of in-time dose meals and meals with missed bolus dose

\begin{tabular}{|c|c|c|c|c|c|c|}
\hline \multirow{2}{*}{$\begin{array}{l}\text { Dose parameter, } \\
\text { estimated mean } \\
(95 \% \mathrm{CI})\end{array}$} & \multicolumn{2}{|c|}{ Baseline level $(n=30)$} & \multicolumn{2}{|c|}{$\begin{array}{l}\text { Follow-up at quarter } \geq 5 \\
(\geq 12 \text { months; } n=14)\end{array}$} & \multirow[t]{2}{*}{$\begin{array}{l}\text { Estimated percentage } \\
\text { change from baseline }\end{array}$} & \multirow[t]{2}{*}{$p$ value } \\
\hline & Daily meals, $n$ & $\begin{array}{l}\text { Proportion } \\
\text { of three } \\
\text { meals, \% }\end{array}$ & Daily meals, $n$ & $\begin{array}{l}\text { Proportion } \\
\text { of three } \\
\text { meals, \% }\end{array}$ & & \\
\hline $\begin{array}{l}\text { MBD meal, per } \\
\text { day }\end{array}$ & $0.73(0.59,0.89)$ & 24.3 & $0.74(0.58,0.93)$ & 24.5 & $0.9 \%(-15.9,21.1)$ & 0.92 \\
\hline $\begin{array}{l}\text { In-time bolus-dose } \\
\text { meals, per day }\end{array}$ & $0.74(0.61,0.90)$ & 24.7 & $0.76(0.60,0.96)$ & 25.3 & $2.7 \%(-15.9,25.4)$ & 0.79 \\
\hline $\begin{array}{l}\text { Undetected meals, } \\
\text { per day }^{a}\end{array}$ & $1.44(1.20,1.64)$ & 47.9 & $1.42(1.15,1.65)$ & 47.4 & $-1.0 \%(-14.1,12.6)$ & 0.88 \\
\hline
\end{tabular}

$C G M$ continuous glucose monitoring, $C I$ confidence interval, $M B D$ missed bolus dose

${ }^{a}$ The algorithm only detected meals with a sharp rise in the CGM signal; therefore, not all meals are detected. Undetected meals were calculated by assuming 3 meals per day and subtracting the number of detected meals from 3

\section{Patient Profiles}

Figure 5 presents three example patient data profiles showing simultaneous downloads from smart pen and CGM data; they demonstrate ways in which these data could help to elucidate the underlying causes of nonoptimal glucose control and form the basis of discussions between HCP and patient. In Fig. 5a, the data illustrate how inadequate glycemic control may result from late bolus insulin timing. When the patient's CGM profile is viewed alongside the dose-timing profile from the smart pen, a rise in glucose is apparent before administration of the bolus insulin injection. In Fig. 5b, injection data from the smart pen highlight the importance of considering the insulin:carbohydrate ratio and applying the correct insulin sensitivity factor when administering bolus insulin doses. The CGM data show that blood glucose levels were often higher than the target glycemic range and the patient needed to administer numerous bolus doses over a 24 -h period. In Fig. $5 c$, the data from the smart pen show that one of the main contributors to lack of glycemic control is omission of the basal dose.

\section{DISCUSSION}

The results of this observational study demonstrate that smart pens have the potential to enhance some aspects of glycemic control in pediatric patients.

During this study, reductions in the total numbers of overall hypoglycemic events and nocturnal hypoglycemic events were observed, suggesting some beneficial effect on glycemic control. Statistically significant reductions from baseline were reported at quarter 4 and $\geq 5$, but not at quarters 2 and 3 . This could reflect gradual improvements in glycemic control after a period of adaptation to smart pen use, during which time the patient/caregiver becomes more confident in its operation and in data interpretation. Consistent with these results, statistically significant reductions from baseline in TBR L2 were also reported at quarter 4 and $\geq 5$. This delayed improvement in glycemic control aligns with the results of a previous study in adult patients [23].

In contrast, no statistically significant changes from baseline were reported for TIR, TAR, and $\% C V$ at quarter $\geq 5$. The nonsignificant changes in TIR and \%CV paralleled the stable number of bolus insulin doses observed during the study: for every additional daily 

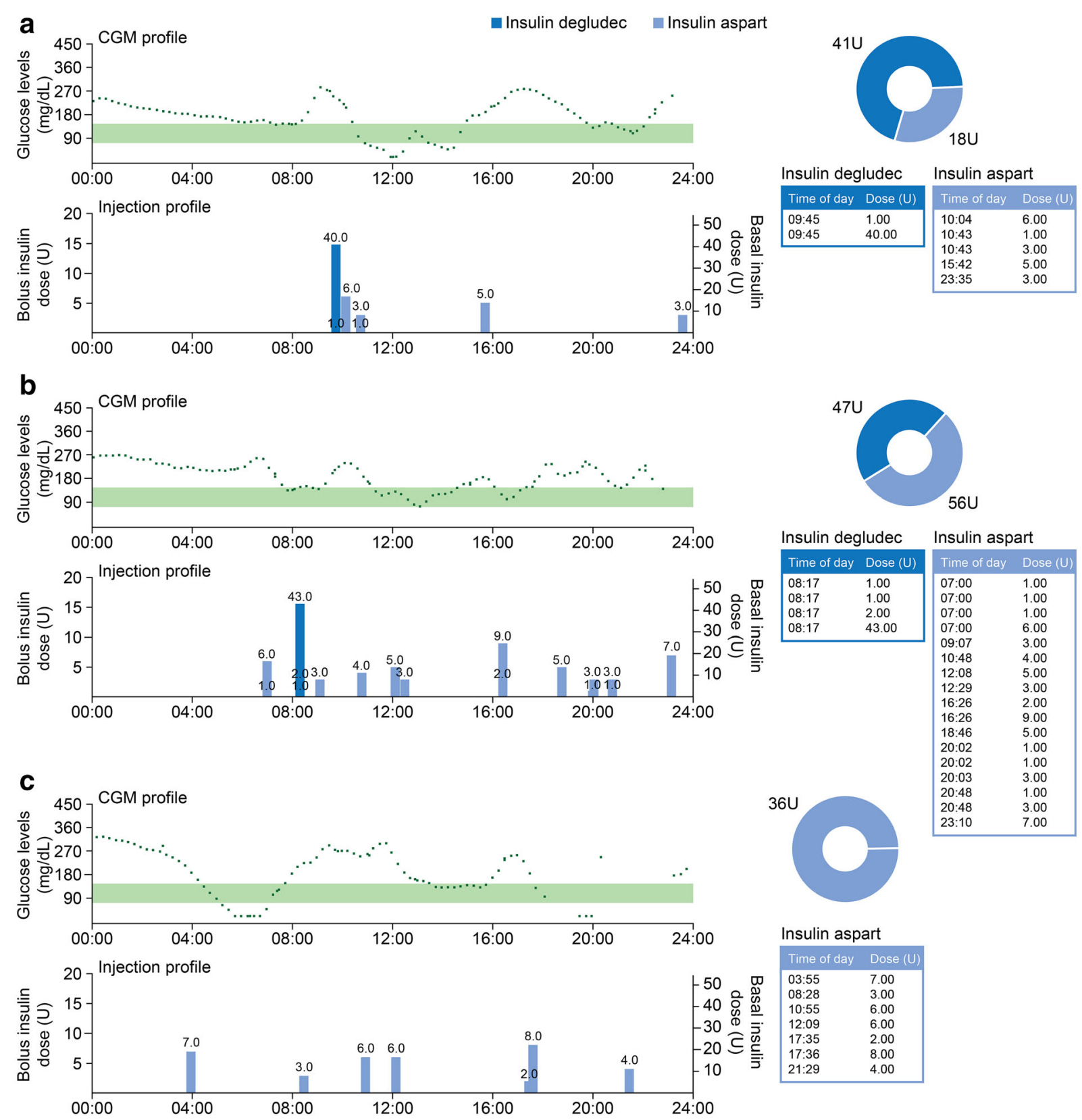

Fig. 5 Example data profiles obtained from combined CGM and smart pens for 3 patients and different factors associated with nonoptimal glucose control: a late bolus insulin timing, $\mathbf{b}$ wrong setting regarding insulin:carbohydrate ratio and insulin sensitivity factor, $\mathbf{c}$ omission of basal

dose. The portion of the graph shaded green represents time in target, a target range commonly used in Sweden $(72-145 \mathrm{mg} / \mathrm{dL} \quad[4.0-8.0 \mathrm{mmol} / \mathrm{L}]) . C G M$ continuous glucose monitoring

bolus dose, HbA1c levels can decrease by approximately $3 \mathrm{mmol} / \mathrm{mol}$ [24]. Additionally, no significant changes from baseline to quarter $\geq 5$ were reported in the mean daily number

of meals with MBDs; however, analyses were restricted to a smaller number of patients.

As demonstrated by the example CGM and injection profiles, visualizing combined data 
from smart pens and CGM devices can help to remove the guesswork around the management of treatment schedules and, thereby, provide a more complete picture of the status of diabetes management for a given individual. The data obtained can enable patient-specific, information-driven discussions to enhance the dialogue between HCPs and patients; such communication has previously been shown to lead to improved self-management [25]. In cases when profiles indicate inadequate glycemic control resulting from mistimed bolus doses or ineffective dosing schedules, discussions between the HCP and patient may focus on bolus-injection timings and dose calculations relative to mealtimes. Furthermore, data showing that a patient frequently misses their basal dose may indicate the need for education and broader discussions between HCP and patient, with consideration given to psychological insulin resistance (some patients may intentionally miss injections because of other factors, such as social factors or fears) [26]. In cases when missed doses occur because patients could not remember if they had taken their dose, impaired glucose control may also be avoided using the memory function in the smart pen.

The availability of technology that provides easy data access may directly improve patient self-management. The ability to download data at home makes it possible to encourage frequent, recurrent evaluations between clinic visits, which could accelerate understanding and behavioral changes. It is anticipated that future data availability through an application could allow patients to track their glycemic levels day-to-day, potentially facilitating better opportunities for reactive and effective self-care. Furthermore, smartphone-application connectivity could offer memory support for those finding it hard to remember their bolus doses (e.g., through the use of push-notifications at their scheduled lunchtime). These systems could also be designed to provide positive feedback, such as credit for taking bolus doses or basal insulin on time.

In a previous study conducted in adult patients with T1D in Sweden, introduction of the smart pen led to significant improvements in glycemic control, including increases in TIR and a reduction in time in hyperglycemia and hypoglycemia L2 [19]. Although similar, positive results for the reduction in hypoglycemia L2 from baseline were observed in this study in children, the trend for increased TIR or reduction in time in hyperglycemia was not replicated. It is to be expected that different trends may be observed in pediatric patients compared with adult patients owing to the various challenges that are unique to treating young patients. For example, in young patients with numerous caregivers, inconsistent or ineffective communication among different caregivers could hinder adaptation to a new treatment plan; more time and more widespread communication may, therefore, be required to observe any improvement in children. Additionally, in adolescents beginning to take responsibility for their own treatment, it could take longer for advice from the HCP to be absorbed and implemented. It is also important to consider the small sample size and patient baseline characteristics when comparing these results with those of previous studies. In this study, the mean percentage TIR at baseline was higher than that reported at baseline in the adult study. As such, the starting point for level of glycemic control may affect the degree of benefit that can be gained from introduction of the smart pen.

Various strengths and limitations should be considered when interpreting these study results. This observational study included a small number of patients in a one-arm design; to confirm these findings, a larger-scale study, conducted over a longer duration to account for device adaptation, will be required. However, despite the low patient numbers, significant changes were detected in some outcomes. Although these data provide insight into the everyday lives of patients, there are limitations inherent in the use of observational real-world data, such as the need to consider the increased uncertainties and variables owing to the greater heterogeneity of the patient population and practices. For example, patients used different basal insulins and CGM devices, which should be considered when interpreting these study results. Because some patients were able to access data at home, there was no way to track 
the frequency of clinic visits to compare the individual histories of the patients in the analysis. Therefore, these data may represent a mixed patient population with the patients varying frequencies of HCP discussions. One further consideration is how age range (9-17 years) across the included patients may have affected the results. The management of diabetes is likely very diverse across this age group, with younger patients relying on caregivers and adolescents beginning self-management, possibly suggesting that a diverse array of patients may benefit from using smart pen devices. However, future studies with larger patient populations may be able to provide a better understanding by analyzing glycemic outcomes with smart pens in stratified age groups. Furthermore, this study did not allow for the administration of insulin in $0.5-\mathrm{U}$ intervals, but this could be considered for future studies. Finally, because there was no defined primary endpoint, these findings were exploratory in nature and should be considered to be hypotheses generating for future research.

\section{CONCLUSION}

This real-world study suggests that introduction of the smart insulin pen could have a positive impact on glycemic control in pediatric patients with T1D by reducing the number of hypoglycemic events (total over $24 \mathrm{~h}$ and nocturnal events) and decreasing the proportion of TBR L2. Larger controlled studies stratified by age may be required to confirm the results of this investigation.

\section{ACKNOWLEDGEMENTS}

We thank the participants of the study.

Funding. This study and Rapid Service Fee was funded by Novo Nordisk A/S. Medical writing support was funded by Novo Nordisk A/S.

Authorship. All named authors meet the International Committee of Medical Journal
Editors (ICMJE) criteria for authorship for this article, take responsibility for the integrity of the work as a whole, and have given their approval for this version to be published.

Author Contributions. All authors were involved in the acquisition, analysis, and interpretation of data, and participated in preparing the manuscript, with the support of medical writing services. All authors read and approved the submitted version of the manuscript.

Medical Writing, Editorial, and Other Assistance. The authors thank Kate Ward from Oxford PharmaGenesis, Oxford, UK, for medical writing support, which was funded by Novo Nordisk A/S.

Prior Presentation. Parts of this study were presented in oral form at the 13th International Conference on Advanced Technologies and Treatment for Diabetes (ATTD), Madrid, Spain, 19-22 February 2020.

Disclosures. Peter Adolfsson is a member of a national advisory board of Novo Nordisk and has received speaker's fees from the same company. Niels Væver Hartvig, Anne Kaas and Jonas Bech Møller are full-time employees of, and hold stock in, Novo Nordisk A/S. Viktor Björnsson and Elsa Ogionwo Lange have nothing to disclose.

Compliance with Ethics Guidelines. Swedish Ethics Committee approval (2019-01,270) was obtained before any studyrelated activities were initiated. Written informed consent was obtained from each participant, allowing Glooko Inc. (Mountain View, CA, USA) to collect data and enabling analyses of the participants' data. The trial was conducted in accordance with the Declaration of Helsinki of 1964 and its latest revision.

Data Availability. The datasets generated during and/or analyzed during the current study cannot be shared publicly within the scope of the consent provided by the patients. 
Open Access. This article is licensed under a Creative Commons Attribution-NonCommercial 4.0 International License, which permits any non-commercial use, sharing, adaptation, distribution and reproduction in any medium or format, as long as you give appropriate credit to the original author(s) and the source, provide a link to the Creative Commons licence, and indicate if changes were made. The images or other third party material in this article are included in the article's Creative Commons licence, unless indicated otherwise in a credit line to the material. If material is not included in the article's Creative Commons licence and your intended use is not permitted by statutory regulation or exceeds the permitted use, you will need to obtain permission directly from the copyright holder. To view a copy of this licence, visit http://creativecommons.org/licenses/by$\mathrm{nc} / 4.0 /$.

\section{REFERENCES}

1. International Diabetes Federation. IDF/ISPAD Global guideline for diabetes in childhood and adolescence 2011. https://www.ispad.org/page/ IDFISPAD2011. Accessed 29 Oct 2021.

2. Sundberg F, Barnard K, Cato A, et al. ISPAD Guidelines. Managing diabetes in preschool children. Pediatr Diabetes. 2017;18:499-517.

3. Chiang JL, Maahs DM, Garvey KC, et al. Type 1 diabetes in children and adolescents: a position statement by the American Diabetes Association. Diabetes Care. 2018;41:2026-44.

4. Hood KK, Peterson CM, Rohan JM, Drotar D. Association between adherence and glycemic control in pediatric type 1 diabetes: a meta-analysis. Pediatrics. 2009;124:e1171-9.

5. Mazarello Paes V, Barrett JK, Taylor-Robinson DC, et al. Effect of early glycemic control on HbA1c tracking and development of vascular complications after 5 years of childhood onset type 1 diabetes: systematic review and meta-analysis. Pediatr Diabetes. 2019;20:494-509.

6. Rawshani A, Sattar N, Franzén S, et al. Excess mortality and cardiovascular disease in young adults with type 1 diabetes in relation to age at onset: a nationwide, register-based cohort study. Lancet. 2018;392:477-86.
7. Lind M, Pivodic A, Svensson A-M, Ólafsdóttir AF, Wedel $\mathrm{H}$, Ludvigsson J. HbA1c level as a risk factor for retinopathy and nephropathy in children and adults with type 1 diabetes: Swedish population based cohort study. BMJ. 2019;366:4894.

8. Davies MJ, Gagliardino JJ, Gray LJ, Khunti K, Mohan V, Hughes R. Real-world factors affecting adherence to insulin therapy in patients with Type 1 or Type 2 diabetes mellitus: a systematic review. Diabet Med. 2013;30:512-24.

9. Wood JR, Miller KM, Maahs DM, et al. Most youth with type 1 diabetes in the T1D Exchange Clinic Registry do not meet American Diabetes Association or International Society for Pediatric and Adolescent Diabetes clinical guidelines. Diabetes Care. 2013;36:2035-7.

10. Streisand R, Monaghan M. Young children with type 1 diabetes: challenges, research, and future directions. Curr Diab Rep. 2014;14:520.

11. Siminerio LM, Albanese-O'Neill A, Chiang JL, et al. Care of young children with diabetes in the child care setting: a position statement of the American Diabetes Association. Diabetes Care. 2014;37:2834.

12. Schwartz FL, Denham S, Heh V, Wapner A, Shubrook J. Experiences of children and adolescents with type 1 diabetes in school: survey of children, parents, and schools. Diabetes Spectrum. 2010;23: 47-55.

13. Kovacs M, Goldston D, Obrosky DS, Iyengar S. Prevalence and predictors of pervasive noncompliance with medical treatment among youths with insulin-dependent diabetes mellitus. J Am Acad Child Adolesc Psychiatry. 1992;31:1112-19.

14. Silverstein J, Klingensmith G, Copeland K, et al. Care of children and adolescents with type 1 diabetes: a statement of the American Diabetes Association. Diabetes Care. 2005;28:186-212.

15. Miller KM, Foster NC, Beck RW, et al. Current state of type 1 diabetes treatment in the U.S.: updated data from the T1D Exchange clinic registry. Diabetes Care. 2015;38:971-8.

16. Klonoff DC, Kerr D. Smart pens will improve insulin therapy. J Diabetes Sci Technol. 2018;12:551-3.

17. Lal RA, Maahs DM. Clinical use of continuous glucose monitoring in pediatrics. Diabetes Technol Ther. 2017; 19:S37-43.

18. Foster NC, Miller KM, Tamborlane WV, Bergenstal RM, Beck RW. Continuous glucose monitoring in patients with type 1 diabetes using insulin injections. Diabetes Care. 2016;39:e81-2. 
19. Adolfsson P, Hartvig NV, Kaas A, Møller JB, Hellman J. Increased time in range and fewer missed bolus injections after introduction of a smart connected insulin pen. Diabetes Technol Ther. 2020;22:709-18.

20. Danne T, Nimri R, Battelino $T$, et al. International consensus on use of continuous glucose monitoring. Diabetes Care. 2017;40:1631-40.

21. Battelino T, Danne T, Bergenstal RM, et al. Clinical targets for continuous glucose monitoring data interpretation: recommendations from the international consensus on time in range. Diabetes Care. 2019;42:1593-603.

22. Harvey RA, Dassau E, Zisser H, Seborg DE, Doyle FJ. Design of the glucose rate increase detector: a meal detection module for the Health Monitoring System. J Diabetes Sci Technol. 2014;8:307-20.

23. Jendle J, Væver Hartvig N, Kaas A, Møller JB, Mårdby AC, Catrina S, editors. Effect of late bolus injections on glycemic variability studied by connected pens. In: American Diabetes Association 80th scientific sessions: a virtual experience; 12-16 June 2020. Diabetes 69(Supplement 1):975-P. https://doi.org/10.2337/db20-975-P.

24. Spaans E, van Hateren KJJ, Groenier KH, Bilo HJG, Kleefstra N, Brand PLP. Mealtime insulin bolus adherence and glycemic control in adolescents on insulin pump therapy. Eur J Pediatr. 2018;177: 1831-6.

25. Heisler M, Bouknight RR, Hayward RA, Smith DM, Kerr EA. The relative importance of physician communication, participatory decision making, and patient understanding in diabetes self-management. J Gen Intern Med. 2002;17:243-52.

26. Peyrot M, Barnett AH, Meneghini LF, SchummDraeger PM. Insulin adherence behaviours and barriers in the multinational Global Attitudes of Patients and Physicians in Insulin Therapy study. Diabet Med. 2012;29:682-9. 